\title{
Prevalence of Peptic Ulcer Disease among the Patients with Abdominal Pain at Tertiary Care Institute of Gujarat
}

\author{
Rahul Charpot ${ }^{\circledR 1}$, Jaydeep M Gadhavi ${ }^{\circledR 2}$ \\ ${ }^{1}$ Associate Professor, Department of Surgery, GMERS Medical College, Sola, Ahmedabad, India, ${ }^{2}$ Associate Professor, Department of Surgery, GMERS Medical College, \\ Gandhinagar, Gujarat, India.
}

\section{Abstract}

Background: To establish the occurrence of peptic ulcer disease amid the Subjects with abdominal pain at tertiary care institute of Gujarat. Subjects and Methods: present research was performed at the Department of Surgery, tertiary care institute of Gujarat, for the period of one year in 200 patients with abdominal pain and diagnosed with peptic ulcer disease. Information was composed utilizing pre-designed questionnaire. Results:The majorities of participants was females, most were aged between 18 to 25 years. Around $97 \%$ had pain in the epigastric region. Gastric ulcers preponderate for $65 \%$ patients in current research, except refused during the later existence of the epoch, as the occurrence of duodenal ulcers stayed stable, however amplified rather the later phase. Conclusion: An extensive diversity of subjects with abdominal pain was documented amid the subjects. On the other hand, the socio-economic situation and educational levels of the Subjects with the illness were below par.

Keywords: Abdominal pain, Epigastric, Peptic ulcer, Socio-economic

Corresponding Author: Jaydeep M Gadhavi, Associate Professor, Department of Surgery, GMERS Medical College, Gandhinagar, Gujarat, India.

E-mail: drjmg75@gmail.com

Received: 24 September 2020

Revised: 30 October 2020

Accepted: 09 November 2020

Published: 27 December 2020

\section{Introduction}

The ulcer is a rupture in the stomach lining, the primary element of the small intestine, or occasionally in the lower esophagus. ${ }^{[1]}$ Just about a $10 \%$ existence danger of rising a peptic ulcer. ${ }^{[2,3]}$ Awaking at nighttime with upper abdominal pain rises with consumption are the majority widespread signs of duodenal ulcer. Extra signs are deprived appetite, weight loss and vomiting. ${ }^{[4,5]}$ Researches have exposed that the mainly widespread grounds are Helicobacter pylori and Nonsteroidal anti-inflammatory drugs. ${ }^{[6]}$ Impediments includes bleeding, perforation, and obstruction of the stomach. ${ }^{[7]}$

NSAIDs reason gastric injury by the damage of the gastric epithelium by intracellular buildup of these drugs in an ionized state. Then it decrease the hydrophobicity of the mucous gel layer by altering the deed of surface active phospholipids pursue by the containment of the prostaglandin fusion which is after that chased by the damage owing to neutrophils obedience to the endothelium of gastric microcirculation. The danger of gastrointestinal bleeding augments sharply with age and the surplus peril from non-aspirin NSAIDs are a lot superior in the old than in young subjects, still when the relative risk is unspecified to stay steady with age. PUD may or may not have symptoms. The difficulties may be life intimidating devoid of any warning signs. The most complication that occurs comprise bleeding and perforation. Bleeding can be together slow and sudden. Perforation usually causes abdominal pain abruptly and typically needs surgery. ${ }^{[8]}$

Earlier researches were based on subjects self-reports through referrals, subsequent form of gastrointestinal symptoms in subjects. The complications of PUD inflict substantial economic and morbidity load on the health organization and the culture. ${ }^{[9]}$ Present study was done to establish the occurrence of peptic ulcer disease amid the subjects with abdominal pain at tertiary care institute of Gujarat, to approximate the occurrence of cases of peptic ulcer disease amid all the patients with abdominal pain presenting the Surgery department, to explain the socio-demographic factors of the subjects with the disease, to decide the forms of peptic ulcer amid diverse age groups. 


\section{Subjects and Methods}

A Cross sectional research performed at the Department of Surgery, tertiary care institute of Gujarat, for the period of one year in 200 patients with abdominal pain and diagnosed with peptic ulcer disease. Every cases of certain analysis of peptic ulcer disease were incorporated in the research. Ethical sanction was granted from the institutional ethical committee and written informed consent was granted from all the contestants. Information was composed utilizing predesigned questionnaire.

\section{Statistical analysis}

The data were analyzed using SPSS version 15. For all tests, confidence level and level of significance were set at $95 \%$ and $5 \%$ respectively.

\section{Results}

A total of 200 patients with a perforated peptic ulcer were recognized. The majorities of contestants was females, the majority were aged amid 18 to 25 years, and had elevated educational level. About (34\%) were employed. [Table 1]

\begin{tabular}{|llll}
\hline \multicolumn{4}{l}{ Table 1: Socio-demographic characters of the studied population } \\
\hline Variable & Number & Percentage \\
\hline Gender & Female & 136 & 68 \\
\hline Age group & Male & 64 & 32 \\
& $18-25$ & 108 & 54 \\
& $26-35$ & 54 & 27 \\
& $36-45$ & 26 & 13 \\
\hline \multirow{5}{*}{ Education } & $46-55$ & 8 & 4.0 \\
& $55+$ & 4 & 2.0 \\
& Primary & 4 & 2 \\
& Secondary & 44 & 22 \\
& University & 148 & 74 \\
& or more & & \\
\hline \multirow{5}{*}{ Occupation } & Preparatory & 4 & 2 \\
& $\begin{array}{l}\text { Not } \\
\text { employed }\end{array}$ & 124 & 62 \\
& Retired & 8 & 4.0 \\
\hline & Employed & 68 & 34 \\
\hline
\end{tabular}

$97 \%$ had pain in the epigastric region. Gastric ulcers outweigh and accounted for $65 \%$ subjects in this research, however turn down through the later years of the phase while the incidence of duodenal ulcers stay stable, but improved rather the later period. Prepyloric ulcers corresponds to $54 \%$ of gastric ulcers and $19 \%$ were situated in the pylorus. In the corpus/fundus area $11 \%$ ulcers were observed, $7 \%$ were located in the antrum.
Table 2: Distribution of the respondents by pain in the epigastric region $[\mathbf{n}=\mathbf{3 0 0}]$

\begin{tabular}{lll}
\hline $\begin{array}{l}\text { Pain in the epigastric } \\
\text { Region }\end{array}$ & Frequency & Percent \\
\hline Yes & 194 & 98 \\
\hline No & 6 & 3 \\
Total & 200 & 100 \\
\hline
\end{tabular}

\section{Discussion}

Peptic ulcer has indisputably been a illness of the twentieth century. Epidemiological data for this disease and its impediments have exposed outstanding biological distinctions in incidence and prevalence. ${ }^{[10]}$ Different features are concerned that play a essential responsibility in the pathogenesis of ulcerations like, sedentary life style, alcohol intake, spicy food, drugs and different bacterial infections. Furthermore, numerous endogenous matters have been recognized and are accounted to be concerned in the making of gastrointestinal lesions in animals. ${ }^{[11]}$ The more significant ones comprise several of the bacterial infection, different drugs and chemicals, gastric secretion, lipid metabolites, neuropeptides, inflammatory mediators and reactive free radicals. The majorities of contestants was females, the majority were aged amid 18 to 25 years, and had elevated educational level. As per research performed in Hawaii, the danger of both gastric and duodenal ulcers gradually augmented with rising pack-years of cigarette smoking. Present research demonstrates that greater part of the respondents had provoked pain when the stomach is bare. Most of the respondents (97\%) had pain in the epigastric region.

Gastric ulcers outweigh and accounted for $65 \%$ patients in this research, but refused during the later years of the phase, while the incidence of duodenal ulcers remained stable, but increased rather the later period. Though, results are superior than result of European endoscopic epidemiologic studies, ${ }^{[12,13]}$ as they accounted prevalence rates from $4.1 \%^{[13]}$ to $6.2 \%$ . In contrast Groenen et al. accounted that duodenal ulcers were diagnosed in $(3.5 \%)$, gastric ulcers were diagnosed in $(2.4 \%){ }^{[14]} \mathrm{As} \mathrm{Li}$ et al. ${ }^{[15]}$ establish in their methodical examination of gastrointestinal diseases, the occurrence of peptic ulcer in China attains $17.2 \%$. This study has some limitations. First of all, the results of the study cannot be extrapolated to the entire population, as it study was conducted at a single center. In future a large sample size and large prospective cohort study should be planned so as to enhance the generalizability of the findings.

\section{Conclusion}

An extensive diversity of subjects with abdominal pain was documented amid the subjects. On the other hand, the socio- 
economic situation and educational levels of the Subjects with the illness were below par.

\section{References}

1. Najm WI. Peptic Ulcer Disease. Prim Care. 2011;38(3):383394. Available from: https://dx.doi.org/10.1016/j.pop.2011.05. 001.

2. Snowden FM. Emerging and reemerging diseases: a historical perspective. Immunol Rev. 2008;225(1):9-26. Available from: https://dx.doi.org/10.1111/j.1600-065x.2008.00677.x.

3. Global, regional, and national age-sex specific all-cause and cause-specific mortality for 240 causes of death, 1990-2013: a systematic analysis for the Global Burden of Disease Study. GBD 2013 Mortality and Causes of Death, Collaborators. 2013;385:117-71.

4. Ramakrishnan K, Salinas RC. Peptic ulcer disease. Am Fam Physician. 2007;76(7):1005-12.

5. Narayanan M, Reddy KM, Marsicano E. Peptic Ulcer Disease and Helicobacter pylori infection. Mo Med. 2018;115(3):219224.

6. Steinberg KP. Stress-related mucosal disease in the critically ill patient: risk factors and strategies to prevent stressrelated bleeding in the intensive care unit. Crit Care Med. 2002;30(6):362-364. Available from: https://doi.org/10.1097/ 00003246-200206001-00005.

7. Milosavljevic T, Kostić-Milosavljević M, Jovanović I, Krstić M. Complications of Peptic Ulcer Disease; 2011. Available from: https://dx.doi.org/10.1159/000331517.

8. Surapaneni S, S R, A VBR. The Perforation-Operation time Interval; An Important Mortality Indicator in Peptic Ulcer Perforation. J Clin Diagn Res. 2013;7(5):880-882. Available from: https://dx.doi.org/10.7860/JCDR/2013/4925.2965.

9. Chung KT, Shelat VG. Perforated peptic ulcer - an update. World J Gastrointest Surg. 2017;9(1):1-12. Available from: https://dx.doi.org/10.4240/wjgs.v9.i1.1.

10. Cosnes J, Gower-Rousseau C, Seksik P, Cortot A. Epidemiology and Natural History of Inflammatory Bowel Diseases. Gastroenterology. 2011;140(6):1785-1794.e4. Available from: https://dx.doi.org/10.1053/j.gastro.2011.01.055.

11. Kusters JG, van Vliet AHM, Kuipers EJ. Pathogenesis of Helicobacter pylori Infection. Clin Microbiol Rev. 2006;19(3):449-490. Available from: https://dx.doi.org/10. 1128/CMR.00054-05.

12. Zagari RM, Law GR, Fuccio L, Pozzato P, Forman D, Bazzoli F. Dyspeptic Symptoms and Endoscopic Findings in the Community: The Loiano-Monghidoro Study. Am J Gastroenterol. 2010;105(3):565-571. Available from: https: //dx.doi.org/10.1038/ajg.2009.706.

13. Aro P, Storskrubb T, Ronkainen J, Bolling-Sternevald E, Engstrand L, Vieth M. Peptic ulcer disease in a general adult population: the Kalixanda study: a random population-based study. Am J Epidemiol. 2006;163:1025-1059. Available from: https://doi.org/10.1093/aje/kwj129.

14. Groenen MJ, Kuipers EJ, Hansen BE. Th Ouwendijk RJ. Incidence of duodenal ulcers and gastric ulcers in a Western population: Back to where it started. Can J Gastroenterol. 2009;23(9):604-612. Available from: https://dx.doi.org/10. 1155/2009/181059.

15. Li Z, Zou D, Ma X, Chen J, Shi X, Gong Y. Epidemiology of peptic ulcer disease: endoscopic results of the systematic investigation of gastrointestinal disease in China. Am J Gastroenterol. 2010;105(12):2570-2577. Available from: https://doi.org/10.1038/ajg.2010.324.

Copyright: (C) the author(s), 2020. It is an open-access article distributed under the terms of the Creative Commons Attribution License (CC BY 4.0), which permits authors to retain ownership of the copyright for their content, and allow anyone to download, reuse, reprint, modify, distribute and/or copy the content as long as the original authors and source are cited.

How to cite this article: Charpot R, Gadhavi JM. Prevalence of Peptic Ulcer Disease among the Patients with Abdominal Pain at Tertiary Care Institute of Gujarat. Acad. J Surg. 2020;3(2):30-32.

DOI: dx.doi.org/10.47008/ajs/2020.3.2.8

Source of Support: Nil, Conflict of Interest: None declared. 